\title{
PENDIDIKAN KESEHATAN TERHADAP PERILAKU GIZI MAHASISWA ILMU KEPERAWATAN STIK SITI KHADIJAH PALEMBANG
}

\author{
Rahmalia Afriyani ${ }^{1}$, Dedi Pahrul ${ }^{2}$, \\ ${ }^{1,2}$ Prodi Ilmu Keperawatan STIK Siti Khadijah \\ Palembang Jalan Demang Lebar Daun Lorok Pakjo \\ Palembang 30117 \\ Email: rahmalia@stik-sitikhadijah.ac.id
}

\begin{abstract}
Abstrak
Masalah yang saat ini dihadapi oleh remaja Indonesia adalah masalah gizi mikronutrien, yakni sekitar $12 \%$ remaja laki-laki dan $23 \%$ remaja perempuan mengalami anemia, yang sebagian besar diakibatkan kekurangan zat besi (anemia defisiensi besi). Pendidikan kesehatan merupakan salah satu cara untuk merubah perilaku yang mengakibatan terjadinya masalah gizi. Penelitian ini bertujuan untuk mengetahui pengaruh pendidikan kesehatan terhadap perilaku gizi seimbang pada mahasiswa keperawatan STIK Siti Khadijah Palembang. Desain penelitian ini adalah quasy eksperiment dengan rancangan one group pre and post test design. Sampel penelitian ini adalah mahasiswi Prodi Ilmu Keperawatan STIK Siti Khadijah Palembang semester I, teknik pengambilan sampel dengan cara total sampling, instrumen dalam penelitian menggunakan kuisioner. Penelitian ini dilaksanakan pada tanggal 23 sampai dengan 30 November tahun 2019 dengan jumlah respon den sebanyak 32 responden. Uji statistik yang digunakan adalah uji Wilcoxon. Hasil penelitian menunjukan bahwa ada pengaruh Pendidikan kesehatan terhadap pengetahuan $(p=0.000)$ dan sikap $(p=0.000)$ gizi seimbang. Maka dari itu perlu ditingkatan penyuluhan dan pendidikan gizi seimbang (mulai dari pesan, fungsi serta prinsip) yang terjadwal dan berkesinambungan.
\end{abstract}

KataKunci : Pendidikan kesehatan, Pengetahuan, Sikap, Gizi Seimbang.

\begin{abstract}
The problem currently faced by Indonesian adolescents was micronutrient nutrition, which is about $12 \%$ of boys and $23 \%$ of girls experienced anemia, mostly due to iron deficiency. Health education is a way to change behavior that results in nutritional problems. This study aimed to determine the effect of health education on balanced nutritional behavior in college student of nursing program in STIK Siti Khadijah Palembang. The design of this research was a quasy experiment study with a one group pretest and post test approach. The subject of this research were $1^{\text {st }}$ semester student of nursing programat STIK Siti Khadijah Palembang, the sampling technique was total sampling with 32 respondents. This research was conducted on $23^{\text {rd }}$ to $30^{\text {th }}$ November 2019 and data analyzed by Wilcoxon test. The results showed that there was an effect of health education on knowledge $(p=0.000)$ and attitude $(p=0.000)$ on balanced nutrition. There fore, it was necessary to improve knowledge and education on balanced nutrition (starting from messages, functions and principles) that were scheduled andsustainable.
\end{abstract}

Keywords: Health education, Knowledge, Attitudes, Balanced Nutrition. 


\section{PENDAHULUAN}

Salah satu masalah yang dihadapi remaja Indonesia adalah, masalah gizi mikronutrien, sekitar $12 \%$ remaja laki-laki dan $23 \%$ remaja perempuan mengalami anemia, yang sebagian besar diakibatkan kekurangan zat besi. Lebih lanjut masalah gizi yang dihadapi remaja saat ini obesitas, stunting dan wasting (anemia defisiensi besi). (Kemenkes RI, 2018)

Wasting atau remaja yang kurus atau kurang energi kronis (KEK) dapat disebabkan karena kurang asupan zat gizi, baik karena alasan ekonomi maupun alasan psikososial seperti misalnya penampilan. Keinginan untuk tampil dengan postur tubuh yang menarik menyebabkan remaja membatasi makan. Perubahan kebiasaan makan yang tidak tepat memungkinkan remaja mengalami gangguan makan dan masalah gizi. Kondisi remaja KEK meningkatkan risiko berbagai penyakit infeksi dan gangguan hormonal yang berdampak buruk di kesehatan. KEK sebenarnya dapat dicegah dengan mengonsumsi makanan bergizi seimbang (Kemenkes, 2018)

Pendidikan kesehatan merupakan salah satu cara untuk merubah perilaku yang mengakibatan terjadinya masalah gizi, menurut Nuryanto, dkk (2014) adapengaruh yang signifikan antara pendidikan kesehatan dengan perilaku gizi pada siswa, pendidikan gizi dapat meningkatan pengetahuan dan perilaku gizi sebesar $75 \%$. Lebih lanjut menurut Sefaya dkk (2017) tingkat pengetahuan gizi responden sebelum dan sesudah penyuluhan mengalamipeningkatan kategori baik pada kelompok perlakuan (54,3\%) lebih baik dibandingkan kelompok kontrol $(2,9 \%)$.

Berdasarkan wawancara singkat dengan beberapa mahasiswa tingkat 1 STIK siti khadijah Palembang, 3 dari 5 orang mahasiswa mengatakan bahwa ia kurang percaya diri terhadap penampilannya, merasa berat badanny kurang ideal dan sedang menjalani program diet dengan meminum teh penurun berat badan dan membatasi makan yaitu sarapan pagi dan makan malam. Untuk itu perlu dilakukan penelitian lebih lanjut tentang pengaruh pendidikan kesehatan terhadap perilaku gizi mahasiswa prodi Ilmu keperawatan di STIK Siti Khadijah Palembang.

\section{METODE PENELITIAN}

\section{Jenis Penelitian}

Penelitian ini merupakan penelitian kuantitatif dan desain yang digunakan dalam penelitian ini adalah Quasy Experiment pretest dan post-test pada satu kelompok saja.

\section{Waktu dan Tempat Penelitian}

Penelitian telah dilakukan pada tanggal 23-30 November 2019 bertempat di STIK siti Khadijah Palembang

\section{Prosedur}

Penelitian ini dilakukan setelah mendapatkan perizinan dari STIK Siti Khadijah Palembang selaku tempat penelitian dan persetujuan dari responden. Pendidikan kesehatan tentang gizi seimbang yang diberikan banyak 1 kali yang memuat pesan, fungsi dan prinsip gizi seimbang. Sebelum diberikan pendidikan kesehatan tentang gizi seimbang, pengetahuan dan sikap responden diukur terlebih dahulu dengan menggunakan kuisioner yang sudah valid dan realiabel. Selanjutnya setelah diberikan Pendidikan kesehatan tentang gizi seimbang maka pengetahuan dan sikap responden diukur kembali dengan menggunakan kuisioner yang sama. Setelah didapatkan data skor pengetahuan dan sikap maka selanjutnya diolah dan dianalisis dengan menggunakan program computer.

\section{Target/ Subjek Penelitian}

Populasi subjek penelitian ini adalah semua mahasiswa program studi ilmu keperawatan STIK Siti Khadijah Palembang tahun akademik 2019/2020 berjumlah 167 orang mahasiswa. Lebih lanjut sampel pada penelitian ini diambil dengan tehnik purposive sampling yaitu seluruh mahasiswa semester I yang belum terpapar Pendidikan 
gizi sebelumnya yang berjumlah 32 orang mahasiswa.

\section{Data, Intrumen, dan Teknik Pengumpulan Data}

Penelitian ini menggunakan data primer yang dikumpulkan dengan cara menyebarkan kuisioner yang sudah valid dan realiabel yang memuat 25 pertanyaan untuk mengukur pengetahuan dan 15 pertanyaan untuk mengukur sikap.

\section{Teknik Analisis Data}

Analisa data pada penelitian terbagi menjadi 2 yaitu analisa univariat untuk mendapatkan distribusi frekuensi dari masing-masing variable dan analisa bivariat dengan menggunakan uji Wilcoxon untuk mengetahui adanya pengaruh pemberian Pendidikan kesehatan terhadap perilaku gizi.

\section{HASIL PENELITIAN Dan PEMBAHASAN}

1. Karakteristik Sampel Penelitian

Distribusi frekuensi untuk masingmasing variabel karakteristik dapat tabel 1

Tabel 1. Distribusi frekuensi karakteristik sampel penelitian $(n=32)$

\begin{tabular}{lcccc}
\hline Variabel Penelitian & Mean & Median & Std. Dev & Min-max \\
\hline Pengetahuan Sebelum & 19.84 & 20 & 1.221 & $18-22$ \\
Pengetahuan Sesudah & 21.22 & 21 & 0.975 & $20-23$ \\
Sikap Sebelum & 9.69 & 10 & 1.061 & $8-12$ \\
Sikap Sesusah & 11.16 & 11 & 0.920 & $9-13$ \\
\multicolumn{1}{c}{ Hasil } & & & & \\
\hline
\end{tabular}

menunjukan bahwa dari total 32 orang responden memiliki sebaran data sebagai berikut: skor pengetahuan sebelum diberikan pendidikan kesehatan yaitu $19.84 \pm 1.221$ dan skor pengetahuan setelah diberikan pendidikan kesehatan adalah 21.22 \pm 0.975 . Kemudian untuk skor sikap sebelum diberikan pendidikan kesehatan adalah $9.69 \pm 1.061$ dan skor sikap setelah diberikan Pendidikan kesehatan adalah 11.16 \pm 0.920 .

\section{Pengaruh Pendidikan kesehatan terhadap perilaku gizi seimbang}

Pengaruh Pendidikan kesehatan terhadap perilaku gizi seimbang dianalisis dengan menggunakan uji Wilcoxon dikarekan data tidak terdistribusi secara normal. Perilaku gizi seimbang tergambar pada pengetahuan dan sikap untuk lebih jelas dapat dilihat pada tabel 2 dan tabel 3.

\section{Tabel 2. Pengaruh Pendidikan Kesehatan Terhadap Pengetahuan Gizi Seimbang}

\begin{tabular}{lccc}
\hline Variabel Penelitian & Median & Min-max & p-value \\
\hline Pengetahuan Sebelum & 20 & $18-22$ & 0.000 \\
Pengetahuan Sesudah & 21 & $20-23$ & \\
Selisih & 1 & & \\
\hline \multicolumn{1}{c}{ Hasil penelitian } & pada tabel 2.
\end{tabular}
menjelaskan bahwa terdapat perbedaan skor pengetahuan sebelum dan sesudah diberikan Pendidikan kesehatan dari total 32. Sebelum mendapatkan pendidikan kesehatan rerata skor pengetahuan 20 dengan skor terendah 18 dan skor tertinggi adalah 22, setelah diberikan Pendidikan kesehatan rerata skor meningkat menjadi 21 dengan skor terendah 20 dan skor tertinggi adalah 23, hasil uji wilcoxon didapatkan nilai $\mathrm{p}: 0.000$ yang berarti bahwa terdapat perbedaan yang signifikan antara skor pengetahuan sebelum dan sesudah diberikan pendidikan kesehatan gizi.

Hasil penelitian ini sejalan dengan penelitian yang dilakukan oleh Nurmasyita, dkk., (2015) bahwa pendidikan gizi dapat meningkatkan skor pengetahuan $9.58 \pm 11.82$, dimana Pendidikan gizi selama 3 bulan menghasilkan perubahan pada variabel penelitian kelompok perlakuan dan control. Pendidikan gizi yang dilakukan secara kontinyu dengan metode pembelajaran di kelas dan materi yang disampaikan disusun dalam buku modul yang dibagikan ke siswa dapat meningkatkan pengetahuan gizi subjek. lebih lanjut menurut hasil penelitian Sefaya, dkk., (2017) terdapat perbedaan yang signifikan skor pengetahuan sebelum 
dan sesudah pada kelompok perlakuan dikarena sebelumnya responden dari kelompok perlakuan tidak banyak mengetahui tentang gizi setelah diberikan penyuluhan terdapat peningkatan nilai sehingga para responden lebih mengetahui tentang gizi.

Menurut Ambarini (2012) Salah satu upaya menanggulangi masalah gizi melalui peningkatan pengetahuan, sikap danperilaku seseorang dengan melakukan penyuluhan gizi. Penyuluhan gizi merupakan suatu prinsip pemasaran yang bersifat edukatif untuk memperbaiki kesadaran gizi dan menghasilkan perilaku peningkatan gizi yang baik. Lebih lanjut menurut Rahman, dkk (2016) pengetahuan gizi menjadi landasan dalam menentukan konsumsi pangan seseorang. Melalui bekal pengetahuan gizi dapat meningkatkan kemampuan seseorang untuk menerapkan pengetahuan gizinya dalam memilihmaupun mengolah bahan makanan sehingga kebutuhan gizi dapat tercukupi.

Berdasarkan hasil penelitian, penelitian terdahulu dan teori penunjang maka peneliti berpendapat bahwa adanya pengaruh Pendidikan kesehatan terhadap perilaku gizi seimbang disebabkan oleh seluruh responden belum pernah terpapar dengan Pendidikan gizi seimbang. Pendidikan kesehatan merupakan salah satu cara untuk meningkatkan pengetahuan hingga mengubah pola pikir responden yang awalnya tidak mengetahui menjadi lebih tahu bagaimana prinsip, pesan dan fungsi gizi seimbang serta zat yang dibutuhkan tubuh dalam pemenuhan kebutuhan energi untuk proses metabolisme. Hal ini secara langsung akan mempengaruhi perilaku gizi seimbang responden tersebut.

Table 3. Pengaruh Pendidikan Kesehatan Terhadap Sikap Gizi Seimbang

\begin{tabular}{lccc}
\hline Variabel Penelitian & Median & Min-max & p-value \\
\hline Sikap Sebelum & 8 & $5-10$ & 0.000 \\
Sikap Sesusah & 11 & $8-13$ & \\
Selisih & 3 & & \\
\hline
\end{tabular}

Hasil penelitian yang terdapat pada tabel 3. menjelaskan bahwa terdapat perbedaan yang signifikan antara skor sikap sebelum dan sesudah. Sebelum diberi pendidikan kesehatan rerata skor sikap adalah 8 dengan skor terkecil 5 dan skor tertinggi adalah 10 sedangkan setelah diberikan Pendidikan gizi rerata skor sikap meningkat menjadi 11 dengan skor paling rendah adalah 8 dan skor paling tinggi adalah 13. Hasil uji Wilcoxon didapatkan nilai $\mathrm{p}=$ 0.000 yang berarti bahwa terdapat perbedaan yang signifikan antara skor sikap sebelum dan sesudah diberikan pendidikan kesehatan gizi.

Hasil penelitian ini sejalan penelitian yang dilakukan oleh Safitri \& Fitrianti (2016) yang menjelaskan bahwa terdapat perbedaan rerata sikap gizi $(\mathrm{p}<0.05)$. Lebih lanjut menurut hasil penelitian Puspitasari, dkk (2015) rata-rata sikap sebelum pendidikan kesehatan sebesar 43,12 dan meningkat menjadi 47,78. Terjadi peningkatan nilai sikap sebesar $9,75 \%$. Peningkatan nilai pada posttest sikap responden menjadikan responden dapat berubah sikap yang pada pretest masih negatif berubah menjadi positif.

Hasil Penelitian ini juga didukung oleh Rahmawati (2014) bahwa sikap kurang dapat berpeluang untuk berperilaku kurang mengenai pemberian makanan yang tepat pada anak, sehingga sikap ibu merupakan faktor yang menentukan seseorang untuk berperilaku memberikan makanan yang tepat agar anak dapat memenuhi kebutuhan gizinya. Menurut Notoadmojo (2012) faktor komponen yang mempengaruhi perubah perilaku salah satu diantaranya adalah sikap. Berdasarkan hasil penelitian, penelitian terkait dan teori penunjang maka peneliti berpendapat bahwa adanya pengaruh pendidikan kesehatan terhadap sikap pada responden disebabkan oleh sikap yang mulanya negatif pada responden dapat berubah menjadi positif terjadi disebabkan oleh adanya pengetahuan yang diperoleh saat diberikan pendidikan gizi, maka responden berpikir bahwa selama ini sikap mememenuhi asupan gizinya masih kurang 
baik. Dengan bersikap positif maka responden berharap bahwa gizi yang dikonsumsi menjadi asupan gizi yang baik yang dapat mendukung kesehatannya.

\section{KESIMPULAN}

Berdasarkan hasil penelitian yang telah dilakukan, maka diperoleh kesimpulan sebagai berikut:

1. Rerata skor pengetahuan sebelum adalah 20 dengan skor terendah adalah 18 dan skor paling tinggi 22, sedangkan setelah diberikan Pendidikan kesehatan rerata skor pengetahuan adalah 21 dengan skor terendah 20 dan skor tertinggi adalah 23,

2. Rerata skor sikap sebelum yaitu 8 dengan skor terendah 5 dan skor tertinggi 10 sedangkan rerata skor sikap sesudah diberikan pendidikan gizi adalah 11 dengan skor terendah 8 dan skor tertinggi 13 ,

3. Ada pengaruh Pendidikan gizi terhadap pengetahuan gizi seimbang $(\mathrm{p}=0,000)$

4. Ada pengaruh Pendidikan gizi terhadap sikap gizi seimbang $(\mathrm{p}=0,000)$

\section{SARAN}

Berdasarkan hasil penelitian maka perlu ditingkatan penyuluhan dan pendidikan gizi seimbang (mulai dari pesan, fungsi serta prinsip) yang terjadwal dan berkesinambungan.

\section{UCAPAN TERIMA KASIH}

Penulis mengucapkan terima kasih kepada semua pihak yang terkait yang telah membantu mendukung terlaksananya penelitian ini.

\section{DAFTARPUSTAKA}

Ambarini, Dyah. (2012) Pengaruh Penyluhan Gizi Terhadap Tingkat Pengetahuan Ibu Mengenai Pemberian Tambahan yang Baik. Surakarta : Skripsi Universitas Sebelas Maret
KemenKes, R.I (2018). Kenali Masalah Gizi yang Ancam Remaja Indonesia. Jakarta: Kemenkes RI

Notoatmodjo, S. (2005). Promosi kesehatan teori dan aplikasi. Jakarta: Rineka Cipta, 52-54.

Nurmasyita, N., Widjanarko, B., \& Margawati, A. (2015). Pengaruh intervensi pendidikan gizi terhadap peningkatan pengetahuan gizi, perubahan asupan zat gizi dan indeks massa tubuh remaja kelebihan berat badan. Jurnal GiziIndonesia (The Indonesian Journal of Nutrition), 4(1),38-

47.Nurachmah, E. (2001). Nutrisi dalam keperawatan. Info Medika. Jakarta.

Nuryanto, P. A., \& Puruhita, N. dkk.(2014). Pengaruh Pendidikan Gizi terhadap Pengetahuan dan Sikap Tentang Gizi Anak Sekolah Dasar. Jurnal Gizi.

Puspitasari, L., Widodo, A., Kep, A., \& Suryandari, D. (2015). Pengaruh Pendidikan Kesehatan Terhadap Perubahan Pengetahuan dan Sikap Ibu Dalam Upaya Menangani Balita Gizi Kurang Di Desa Mancasan Sukoharjo (Doctoral dissertation, Universitas MuhammadiyahSurakarta).

Rahman, N., Dewi, N. U., \& Armawaty, F. (2016). Faktor-faktor yang berhubungan dengan PerilakuMakan pada Remaja SMA Negeri 1 palu. PREVENTIF: Jurnal Kesehatan Masyarakat,7(1).

Rahmawati, I., Sudargo, T., dan Paramastri, I. 2006. Jurnal Gizi Klinik Indonesia. Yogyakarta: Fakultas Kedokteran UGM

Safitri, N. R. D., \& Fitranti, D. Y. (2016). Pengaruh edukasi gizi dengan ceramah dan booklet terhadap peningkatan pengetahuan dansikap gizi remaja overweight (Doctoral dissertation, Universitas Diponegoro). 
Sefaya, K. T., Nugraheni, S. A., \& Pangestuti, D. R. (2017). Pengaruh Pendidikan Gizi terhadap Pengetahuan Gizi dan Tingkat Kecukupan Gizi Terkait Pencegahan Anemia Remaja (Studi pada Siswa Kelas XI SMA Teuku Umar Semarang. Jurnal Kesehatan Masyarakat (e-Journal), 5(1), 272282. 